Gut, $1975,16,365-371$

\title{
Serum antibodies in human pancreatic disease
}

\author{
R. LENDRUM AND GEOFFREY WALKER ${ }^{1}$ \\ From the Department of Gastroenterology, St Mary's Hospital, London
}

SUMMARY An immunofluorescent study of sera from patients with various pancreatic diseases and from controls was carried out using human pancreas as substrate. A reproducible pattern of immunofluorescence, consisting of a coarse granular appearance in the cytoplasm of acinar cells of the pancreas and independent of the ABO blood group system, was found. This occurred in 21 of 61 patients with acute pancreatitis; it was not found in other pancreatic diseases, and occurred in only four of 170 control subjects consisting of mixed hospital patients and healthy adults. Preliminary absorption experiments suggest that the antigen is located in the microsomal fraction of pancreatic homogenates and may be organ-specific. The relationship of positive antibody tests to aetiological factors is discussed.

Studies of naturally occurring antibodies in human pancreatic disease have produced conflicting results. Circulating antibodies reacting with human pancreatic homogenates, and detected by precipitation or gel-diffusion methods (Thal, Murray, and Egner, 1959; Fonkalsrud and Longmire, 1961; Herskovic, Alarçón-Segovia, Bartholomew, Cain, and Wakim, 1966) or tanned-cell haemagglutination (Murray and Thal, 1960) have been reported in chronic pancreatitis, cystic fibrosis, and carcinoma. However, these findings have not been confirmed (Metzgar, 1964a; Stein, Manlapas, Soike, and Patterson, 1964; Rose, 1965; Villavicencio, Thurnau, and Goetz, 1965). In acute pancreatitis, positive reactions have been restricted to isolated cases where precipitins in the serum have been described (Fonkalsrud and Longmire, 1961; Herskovic et al, 1966). There are no reports of immunofluorescent studies in these conditions. The present work employs such methods in an investigation of pancreatic diseases in man.

\section{Materials and Methods}

PATIENTS AND SERA

Blood samples were collected from 61 patients with acute pancreatitis (serially over several weeks where possible), 12 patients with relapsing acute pancreatitis, 14 patients with chronic pancreatic disease (11 chronic pancreatitis, one idiopathic haemochromatosis, two pancreatic exocrine deficiency), 13

${ }^{1}$ Please send requests for reprints to Dr Geoffrey Walker, Department of Gastroenterology, St Mary's Hospital, London W2.

Received for publication 24 February 1975. patients with pancreatic neoplasms, and 12 healthy adults. Blood bank sera from 461 mixed hospital patients without evident pancreatic disease and from 78 healthy antenatal subjects were also studied. Sera were stored at $-20^{\circ} \mathrm{C}$.

\section{TISSUES}

Human pancreas was obtained at operation, at the time of cadaveric renal transplant procedures, and at necropsy. Adult and baby tissues were examined. Surgical specimens were immediately processed in the operating theatre. After removal of unwanted connective tissue, $0.5 \mathrm{~cm}$ cubes were prepared and frozen in isopentane cooled in liquid nitrogen and thereafter stored at $-70^{\circ} \mathrm{C}$. Rat and guinea-pig pancreas, rat liver and kidney, and operative human thyroid and stomach, similarly prepared, were also studied.

\section{ANTISERA}

Fluorescein-isothiocyanate (FITC)-conjugated sheep and goat antisera to human whole immunoglobulin, IgA, IgG, and IgM, and goat and swine antisera to human betalc were obtained from Wellcome and Nordic laboratories. Optimal working dilutions of these reagents were usually found to be $1: 8$, but with the swine anti-beta 1 , $1: 12$ dilutions were employed.

\section{IMMUNOFLUORESCENT METHODS}

An indirect immunofluorescent technique based on the methods of Roitt and Doniach (1969) was used. Unfixed cryostat sections 5 micrometres thick were cut at $-20^{\circ} \mathrm{C}$, dried at room temperature for $30 \mathrm{~min}$ - 
utes, and stored at $-70^{\circ} \mathrm{C}$; they were dried again for 30 minutes before use. Serum was applied for 20 minutes and then washed off in running barbitone buffer, $\mathrm{pH} 7 \cdot 2$. The sections were then washed mechanically, with buffer, for a further 20 minutes. Conjugated antisera were then applied for 20 minutes and the sections washed as before. Slides were mounted in glycerol/glycine buffer, $\mathrm{pH} 8.6$, and examined with a Leitz Orthoplan microscope fitted with incident illumination. A $5 \mathrm{~mm}$ BG12 excitation filter and a K460 suppression slide filter were used. Photographs were taken with an Orthomat camera using high-speed Ektachrome (Tungsten) film.

\section{COMPLEMENT FIXATION}

Test sera, heated to $56^{\circ} \mathrm{C}$ for 30 minutes, were mixed with an equal volume of fresh human serum known to be unreactive with human pancreas in an antiglobulin test. The indirect staining procedure was then carried out as described, using conjugated antibetalc. Parallel control tests were performed using equal volumes of heated test serum and heated fresh serum. Heated positive sera, diluted 1:2, were also tested with conjugated antiglobulin, to ensure that the heating had not affected potency. The specificity of the anti-betalc was confirmed in concurrent tests using serum positive for gastric parietal cell antibodies applied to human stomach (Johnson and Holborow, 1973).

\section{ABSORPTION OF POSITIVE SERA WITH HUMAN RED CELLS}

Red cells of blood groups $\mathrm{O}, \mathrm{A}$, and B (all Rhesus negative (Rh-) cde/cde), ORh + (CDe/cDE) and ORh - (Kell-positive), which had been stored in acid citrate dextrose at $+4^{\circ} \mathrm{C}$, were washed three times in buffered saline. Equal volumes of packed red cells and undiluted sera were mixed and allowed to react at $+4^{\circ} \mathrm{C}$ for 30 minutes (Mollison, 1972a). Control (positive) sera were absorbed with an equal volume of saline. Sera found to be unaffected by the above process were more intensively absorbed using an equal volume of red cells for two hours at $37^{\circ} \mathrm{C}$, followed by a change of red cells and further absorption overnight at $4^{\circ} \mathrm{C}$.

\section{ABSORPTION OF POSITIVE SERA WITH SALIVA}

Saliva was collected from group $\mathbf{O}(\mathbf{R h}+)$ laboratory personnel of Lewis phenotypes $\mathrm{Le}(\mathrm{a}+\mathrm{b}-)$, $\operatorname{Le}(a-b+)$, and $\operatorname{Le}(a-b-)$. Samples were frozen for three days at $-20^{\circ} \mathrm{C}$, centrifuged, and boiled for 10 minutes to destroy enzymes (Mollison, 1972b). Equal volumes of saliva and test serum were mixed and allowed to react at room temperature for 15 minutes before centrifuging and testing. A control
anti-Le ${ }^{\mathfrak{a}}$ serum (kindly provided by Professor Mollison) was absorbed with each of the three saliva specimens, and all sera were in addition absorbed with saline only as controls.

\section{TISSUE FRACTIONATION STUDIES}

Fresh human pancreas obtained at the time of cadaveric renal transplant procedures was used. Fractionation was based on the method of Hokin (1955). All processes were carried out in an ice bath, and centrifuge temperatures were kept at $+4^{\circ} \mathrm{C}$ to limit enzyme activity. Batches of approximately $10 \mathrm{~g}$ of tissue were suspended in $0.25 \mathrm{M}$ sucrose, $\mathrm{pH} 5 \cdot 5$, $1.0 \mathrm{ml}$ of sucrose being used for each gram of original tissue. Enzyme inhibitors were added as described by Banwo, Versey, and Hobbs (1974) with additional aprotinin (Trasylol), as it had been found in preliminary experiments that this did not interfere with fluorescence (final inhibitor concentrations were epsilon-amino-caproic acid (EACA) $0.6 \% \mathrm{w} / \mathrm{v}$, aprotinin 100 kallikrein inactivator units $/ \mathrm{ml}$ ). Homogenization was performed in a glass tube with a rotating Teflon pestle. Fibrous tissue was removed by filtration through nylon mesh, and an aliquot of the whole homogenate was removed at this stage. Pellets isolated after centrifugation at $600 \mathrm{~g}$ for 10 minutes, $1000 \mathrm{~g}$ for 10 minutes, $6000 \mathrm{~g}$ for $20 \mathrm{~min}$ utes, and $100000 \mathrm{~g}$ for one hour were regarded as nuclear, zymogen granule, mitochondrial, and microsomal fractions respectively. The soluble supernatant was also retained. Each pellet was washed twice in sucrose plus inhibitor and finally resuspended in this medium using $0.1 \mathrm{ml}$ per $\mathrm{g}$ original tissue. In one experiment human liver obtained also at the time of cadaveric renal transplant was subjected to the same procedure.

Aliquots of sera, known to react with human pancreas at $1: 10$ dilution, were diluted $1: 5$ in barbitone buffer and absorbed overnight at $+4^{\circ} \mathrm{C}$ on a moving table with an equal volume of each of the six fractions described above. Before testing, each aliquot was centrifuged at $100000 \mathrm{~g}$ for one hour. Control sera were absorbed only with sucrose containing inhibitor.

\section{Results}

Initial tests using 1:10 serum dilutions applied to both fresh and postmortem pancreases revealed a granular pattern of immunofluorescence affecting the cytoplasm of acinar cells. This appearance was distinct from that produced by sera from patients without pancreatic disease and known to contain anti-nuclear, -smooth muscle, -mitochondrial, -reticulin, or renal tubular brush-border antibodies. The brightest immunofluorescence was obtained using 
pancreas from two babies who died aged approximately 3 months. This pattern occurred with sera from 12 of 61 patients with acute pancreatitis, one of 13 patients with carcinoma of the pancreas, three of 381 patients without evidence of pancreatic disease, and one of 12 healthy adults. Nine of the positive sera from the pancreatitis patients, and that from the healthy control, reacted with pancreases of blood groups $\mathrm{A}, \mathrm{B}$, and $\mathrm{O}$. The remaining seven positive sera did not react with group $O$ pancreas even at a dilution of 1 in 2 .

\section{ABSORPTION STUDIES WITH RED CELLS}

The immunofluorescence produced by the seven sera which reacted only with A or B pancreases could be markedly reduced or abolished by prior absorption with red cells of the same blood group. Positive sera from six of the acute pancreatitis patients, and from the healthy control, which reacted with pancreases of all three blood groups, were absorbed for 30 minutes with red cells of groups $\mathrm{A}, \mathrm{B}$, and $\mathrm{O}$ (all $\mathrm{Rh}-$ ) and $O(R h+)$. Five of these sera were further absorbed at $37^{\circ} \mathrm{C}$ and at $4^{\circ} \mathrm{C}$. The fluorescence produced by these sera with pancreases of all blood groups was unaffected by these procedures, except in one case where both $\mathrm{O}(\mathrm{Rh}-)$ and $\mathrm{O}(\mathrm{Rh}+)$ cells abolished immunofluorescence with group $O$ pancreas but did not affect fluorescence with A or B pancreas. The reasons for this are obscure. In two other subjects, absorption with group A cells diminished fluorescence with group A pancreas, and in one of these B cells diminished fluorescence with B pancreas. The only positive serum tested with $\mathrm{O}(\mathrm{Rh}-)$-Kell-positive red cells was unaffected by this procedure.

Thus, with only one exception, absorption with red cells of groups $\mathbf{A}, \mathbf{B}$, and $\mathrm{O}$ did not have any effect on positive immunofluorescence reactions produced on $\mathrm{O}$ pancreases.

\section{ABSORPTION WITH SALIVA}

Three positive pancreatitis sera were absorbed with saliva of the three Lewis phenotypes without reduction in fluorescence on $\mathrm{A}, \mathrm{B}$, or $\mathrm{O}$ pancreas. The control anti-Le $\mathrm{e}^{\mathrm{a}}$ serum, however, produced a different fluorescent pattern on pancreas, and this was readily abolished by absorption with $\operatorname{Le}(\mathrm{a}+\mathrm{b}-)$ and $\operatorname{Le}(a-b+)$ but not $\operatorname{Le}(a-b-)$ saliva. Thus again, Le ${ }^{\mathrm{a}}$ substances cannot be responsible for the immunofluorescent reactions described.

IMMUNOFLUORESCENT REACTIONS DUE TO

ANTI-A AND ANTI-B BLOOD GROUP

ANTIBODIES

In order to determine the frequency of reactions caused by anti-A and anti-B blood-group anti- bodies, 40 further blood bank sera known to be unreactive with group $O$ pancreas were tested undiluted against $A$ and $B$ pancreases. Sixty-two per cent of these sera produced positive immunofluorescence. Details of the reactions appear in table I. In subsequent experiments, therefore, only pancreases of blood group $\mathrm{O}$ were used.

\begin{tabular}{lcccc}
\hline $\begin{array}{l}\text { Blood Group } \\
\text { of Serum }\end{array}$ & $\begin{array}{l}\text { Number of } \\
\text { Sera Tested }\end{array}$ & \multicolumn{3}{l}{$\begin{array}{l}\text { Positive Results in Pancreases of Different } \\
\text { ABO Groups }\end{array}$} \\
\cline { 2 - 5 } & & $A$ & $B$ & $O$ \\
\hline A & 8 & 0 & 2 & 0 \\
B & 6 & 2 & 0 & 0 \\
O & 26 & 11 & 14 & 0 \\
\hline
\end{tabular}

Table I Incidence of acinar-cell cytoplasmic fluorescent reactions caused by ant $i-A$ and ant $-B$ blood group ant $i$ bodies in 40 undiluted blood bank sera tested against pancreases of different $A B O$ groups

\section{FLUORESCENCE WITH BLOOD GROUP O PANCREAS}

Sera from the patients with pancreatic disease, from 80 further mixed hospital patients and 78 healthy ante-natal patients, and from the 12 healthy controls were now tested undiluted against group $O$ pancreas.

A granular pattern of fluorescence affecting acinar cell cytoplasm was again found frequently ( 21 out of 61 patients) in acute pancreatitis but rarely in other subjects (table II). Individual cells were stained to varying degrees, and not all cells were affected (fig 1). Islet tissue was uniformly negative on immunofluorescence. These positive sera reacted with pancreas of all three blood groups.

\begin{tabular}{lll}
\hline No. of Subjects Studied & & $\begin{array}{l}\text { No. Showing Acinar } \\
\text { Fluorescence }\end{array}$ \\
\hline Acute pancreatitis & 61 & 21 \\
Relapsing pancreatitis & 12 & 0 \\
Chronic pancreatic disease & 14 & 0 \\
Carcinoma of pancreas & 13 & 0 \\
Antenatal patients & 78 & 1 \\
Mixed hospital patients & 80 & 2 \\
Healthy adults & 12 & 1 \\
\hline
\end{tabular}

Table II Incidence of acinar cytoplasmic fluorescent reactions using undiluted sera against pancreas of blood group $O$.

Among the pancreatitis patients whose sera showed this pattern were eight in whom the antibody was undetectable in undiluted serum taken 11 days or less after the onset of the illness; a further four showed an increase in titre during the second week (figs 1 and 2). The antibody has persisted for 10 


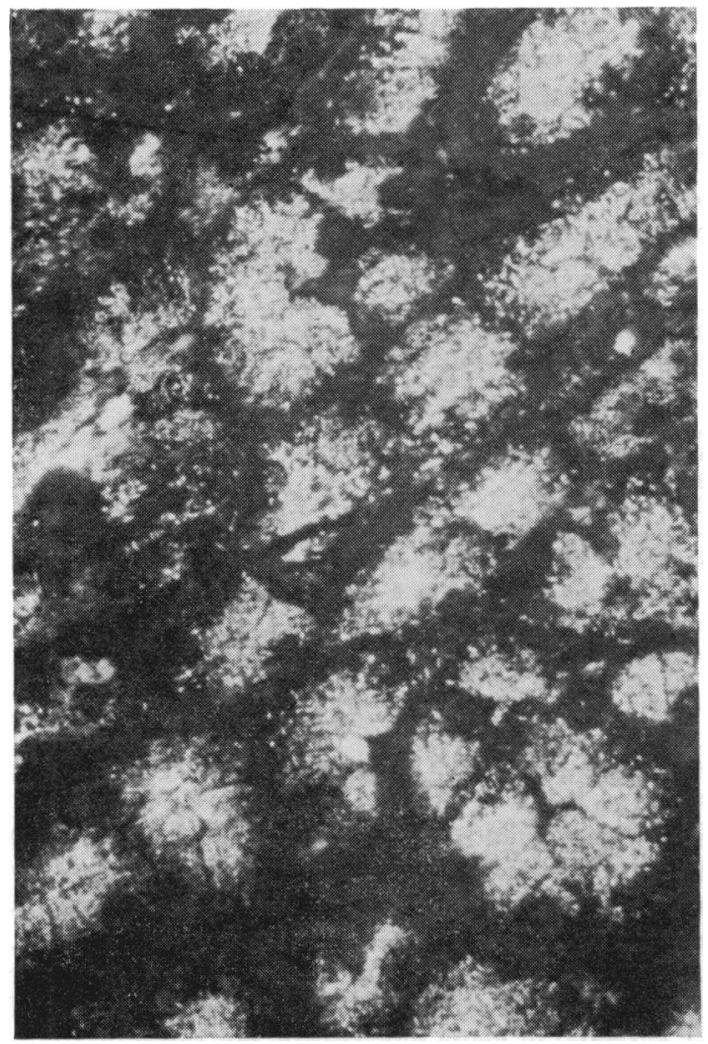

Fig 1 Human pancreas from blood group $O$ subject treated with a 1:10 dilution of serum obtained 12 days after the onset of acute pancreatitis in a patient of blood group A; followed by FITC-conjugated sheep antihuman whole immunoglobulin, diluted $1: 8$.

There is coarse granular fluorescence of the acinar-cell cytoplasm. $\times 480$.

months in one patient followed serially, whereas it had disappeared in three patients tested six weeks, seven weeks, and eight months respectively after the onset of illness.

In pancreatitis patients, antibody titres were usually 1 in 1 to 1 in 10, although one subject produced a reaction at 1 in 80 . 'Control' positives were always $1: 1$ except in one healthy adult $(1: 10)$.

The immunoglobulin classes of the antibodies were IgG (one patient), IgA (seven patients), or both (13 patients) in those with pancreatitis, and IgM (one subject) or IgG (three subjects) among the controls.

Complement fixation was demonstrated in only one of 15 positive sera tested (14 pancreatitis; one control) and this subject had pancreatitis. Heating to $56^{\circ} \mathrm{C}$ did not affect the reaction of positive sera with pancreas in conjugated antiglobulin tests.

TISSUE SPECIFICITY OF

IMMUNOFLUORESCENT REACTIONS

Pancreatitis sera giving positive immunofluorescence with human pancreas were also tested against human thyroid and stomach and against rat liver and kidney, at a dilution of $1: 10$. They did not produce any consistent or characteristic pattern when tested against these tissues and 10 of them, including two which reacted at 1 in 10 dilution with pancreas, produced no reaction at all. Among the remaining 11 patients, renal tubular brush border (6), antinuclear (5), smooth muscle (3), antireticulin (2), or gastric parietal cell (1) antibodies were identified, either singly or in combination.

SPECIES SPECIFICITY

The interpretation of immunofluorescent patterns

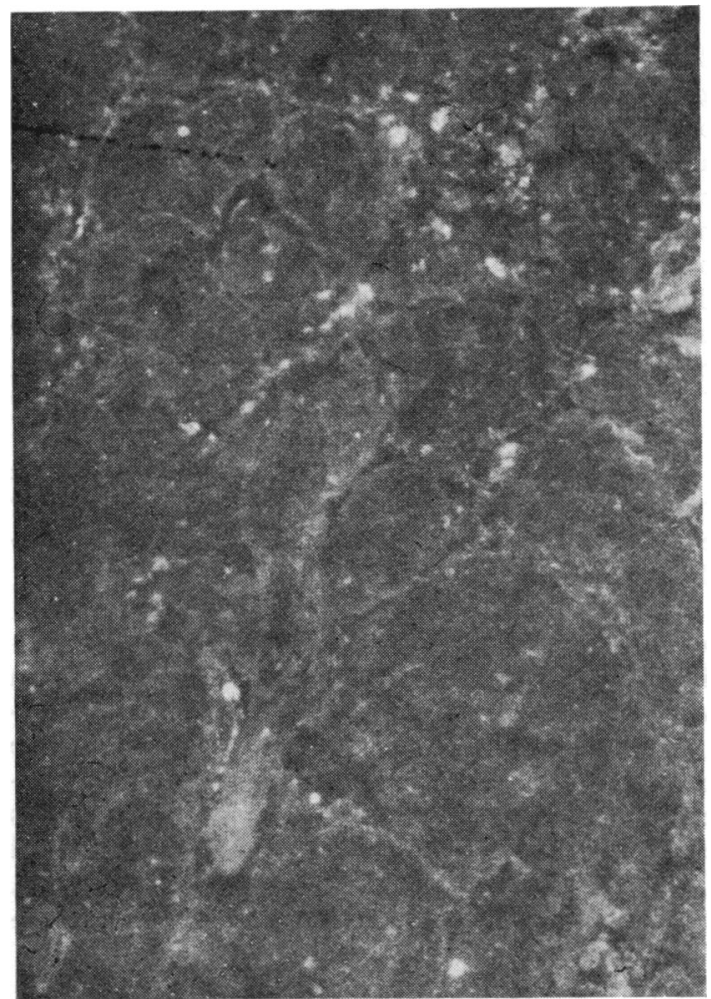

Fig 2 The same pancreas as in fig 1 treated with 1:10 diluted serum, from the same patient as in fig 1, taken six days after the onset of acute pancreatitis; followed by FITC-conjugated sheep antihuman whole immunoglobulin, diluted 1:8. Negative result. $\times 480$. 
on rat pancreas was difficult owing to a slight granularity of the cytoplasm frequently produced by normal sera. In a single batch of tests, one of eight sera giving positive immunofluorescence with human pancreas produced definite acinar fluorescence with rat pancreas, compared with none of eight healthy control sera. The positive patient had acute pancreatitis. This serum also differed from other positive sera in that it fixed complement with human pancreas.

All sera tested with guinea-pig pancreas gave a bright fluorescence of central acinar secretions, and a variably granular appearance of the surrounding acinar cells. Sera positive with human pancreas did not differ from controls.

\section{TISSUE FRACTIONATION AND ABSORPTION} EXPERIMENTS

On light microscopy, nuclei were clearly identifiable in the $600 \mathrm{~g}$ fractions, and round particles corresponding with the zymogen granules described by Hokin (1955) were seen in the $1000 \mathrm{~g}$ fractions from pancreas but not from liver. Electron microscopic confirmation of the composition of the mitochondrial and microsomal pellets was not carried out.

Two positive sera, subsequently shown to react with pancreas of all three blood groups, were absorbed with pancreatic subfractions and tested against postmortem baby pancreas. Fluorescence was markedly reduced or abolished by the whole homogenate and by microsomal and soluble fractions; slightly reduced by the mitochondrial fraction; and unaffected by the nuclear and zymogen granule fractions.

Absorption was repeated with one of these sera, using both liver and pancreas subfractions from a second donor. Fluorescence was abolished by the whole homogenate and microsomal fractions of pancreas, and reduced by the soluble supernatant fraction; the other pancreatic fractions and the liver fractions were without effect.

\section{CLINICAL FEATURES OF SUBJECTS SHOWING} ACINAR CELL FLUORESCENCE

The 21 pancreatitis patients showing acinar cell fluorescence with group $\mathbf{O}$ pancreas were composed of 16 men aged 19 to 73 years and five women aged 26 to 69 years. Their associated clinical conditions are summarized in table III; one-third of them had no evident cause for pancreatitis. These patients did not appear to differ from those without antibodies in terms of the duration or severity of the disease. Only three had received blood or plasma transfusions.

The two 'mixed hospital control' patients giving positive results were a man aged 66 years with myelofibrosis who had received multiple blood transfusions, and a recently transfused man aged 58

\begin{tabular}{lll}
\hline Associated Findings & No. of Patients & $\begin{array}{l}\text { No. Showing } \\
\text { Acinar Fluorescence }\end{array}$ \\
\hline Biliary disease & 15 & 4 \\
Alcohol & 13 & 8 \\
Diabetes & 6 & 1 \\
Recent abdominal opera- & 4 & 0 \\
$\quad$ tion & 1 & 1 \\
Carcinoma of pancreas & 1 & 7 \\
None & 22 & \\
\hline
\end{tabular}

Table III Associated clinical features in 61 patients with acute pancreatitis and their relationship to acinar-cell fluorescence with pancreas of blood group $O$

years with unexplained haematemesis and congestive heart failure. The healthy antenatal subject was aged 27 years, and the healthy adult was a male aged 30 ; in the latter, positive sera were obtained during a four-week period, but two months later the antibody had disappeared and has remained absent during a year of follow-up. None of these four control patients had any past history or current evidence of pancreatic disease. Serum amylases were normal at the time of positive immunofluorescence tests.

\section{OTHER IMMUNOFLUORESCENT PATTERNS}

ON HUMAN PANCREAS

Two non-organ-specific patterns of uncertain significance, which were also independent of ABO blood groups, were found in two isolated control patients. A 57-year-old woman with ulcerative colitis but without evidence of pancreatic disease showed a homogeneous fluorescence with human and rat pancreas to a titre of 1 in 20 . Her serum also reacted with rat liver, but not with rat kidney. Thyroid cytoplasmic antibodies were also present. The antibody was of IgG class. Serum from a 58-year-old man with peripheral vascular disease produced a fine interlacing linear fluorescence with human pancreatic acinar cells, and with both islet and acinar tissue of guinea-pig pancreas, to a titre of 1 in 80 . A similar pattern occurred on thyroid epithelial cells. The reaction was positive with anti-IgG conjugate, but was destroyed by heating to $56^{\circ} \mathrm{C}$ for 30 minutes.

\section{OTHER ANTIBODIES IDENTIFIED IN}

PANCREATITIS PATIENTS

Recognized autoantibody patterns detected on human thyroid and stomach and rat liver and kidney occurred in 31 of the 61 patients with acute pancreatitis and included renal tubular brush-border (18), antinuclear (12), smooth muscle (6), gastric parietal-cell (6), anti-reticulin (3) and thyroid cytoplasmic (2) antibodies. Thirty patients were negative for all reactions. Positive reactions were equally distributed between acinar-cell positive and negative reactors. 


\section{Discussion}

The initial studies showed that a proportion of immunofluorescence reactions with human pancreas are due to anti-A and anti-B blood group antibodies. This is important, since $\mathbf{A}$ and $\mathbf{B}$ pancreases are likely to give confusing results in any search for pancreas-specific antibodies. Szulman (1960 and 1962) demonstrated A, B, and $H$ antigens in human pancreas by immunofluorescence using high-titre antisera : the acinar cells, but not the islets or the duct systems, possessed these antigens, and the fluorescent pattern was granular. Although islet cell fluorescence due to blood group A substance has been described on infant pancreas (Glynn and Holborow, 1959), we have not encountered islet immunofluorescence from this cause nor has islet fluorescence such as that described in diabetes with autoimmunity been seen in our series (Bottazzo, Florin-Christensen, and Doniach, 1974; MacCuish, Barnes, Irvine, and Duncan, 1974).

The immunofluorescence occurring with group $O$ pancreas was very similar in appearance to that produced by blood group antibodies, but with one exception, sera showing this pattern were not affected by absorption with A, B, O, Rh +, or Kell + red cells, and the antibody could not be absorbed by $\mathrm{Le}^{\mathrm{a}}$ substance in saliva; the antigen is therefore unlikely to be related to these blood group substances. Tissue absorption studies with two of the sera suggest that the antigen is related to the microsomal cell fraction of pancreas and the failure of liver subfractions to absorb the antibody suggests that it is pancreasspecific.

This antibody, reacting with pancreas of all three blood groups, has a strong association with acute pancreatitis. The appearance of the antibody for the first time during the second week of illness in several of our patients, and its subsequent disappearance in three of them, strengthens this association. One explanation for the absence of antibody in the early stages of the illness might be that high levels of circulating enzymes cause destruction of immunoglobulin. It is also possible that the antibodies may arise simply as a consequence of tissue damage. The incidence of immunofluorescence observed in acute pancreatitis in the present study may have been an underestimate of the true incidence in that 16 of the negative pancreatitis patients had only single blood samples examined at varying times after the clinical onset of their illness.

The precise nature of the antigen with which this antibody reacts is not yet clear. The cytoplasmic, granular nature of the fluorescence suggested initially that the zymogen granules might be implicated. Antibodies to various pancreatic enzymes have been used in immunofluorescent studies of pancreas in cows and pigs (Marshall, 1954; Moon and McIvor, 1960; Yasuda and Coons, 1966); several of these were reported as producing granular patterns. The relationship of these findings to our results in man is unclear. Hokin (1955) found that zymogen granules isolated from a dog pancreas homogenates at $1000 \mathrm{~g}$ would remain stable at $\mathrm{pH} 5.5$, but would lyse at more alkaline $\mathrm{pH}$. Similar fractionation techniques have been applied to pancreases from mice (Van Lancker and Holtzer, 1959), rats (Laird and Barton, 1957; Rothman, 1971), and cows (Greene, Hirs, and Palade, 1963). After a similar procedure with human pancreas we have found that the $1000 \mathrm{~g}$ fraction shows spherical particles on light microscopy which presumably represent zymogen granules. However, the immunofluorescence produced by the present antibody was not affected by absorption with this fraction, under conditions of $\mathrm{pH}$ which would be expected to lyse the granules. Enzymes are therefore unlikely to be the antigens concerned.

In animals, antibodies reacting with the pancreas have been produced by immunization with pancreatic homogenates (Thal, et al, 1959; Witebsky, Rose, and Nadel, 1960; Fonkalsrud and Longmire, 1961) and Thal et al (1959) suggested that these were isoantibodies. The isoantigens of rabbit pancreas have been localized by immunofluorescence to the apical portion of acinar cells (Metzgar, 1964b) and some of their physicochemical properties have been defined (Rose, 1965). Their exact nature, however, remains uncertain. A similar system of isoantigens in human pancreas has been identified by the immunization of Rhesus monkeys (Metzgar, 1964a). However, in the present study, sera reacting with group $O$ pancreas have produced positive fluorescent tests with all pancreas tissues studied, thus making it unlikely that these reactions can be attributed to isoantibodies. The relationship, if any, between the antibodies described in the present work and those produced in the above animal experiments is unknown. The species-specificity of the antibody currently described remains in some doubt owing to certain technical difficulties on immunofluorescence discussed earlier (see Results). The answer to this question must await results of absorption experiments with animal pancreas homogenates.

It is unlikely that the major difference in incidence of immunofluorescence observed in the sera from patients with acute pancreatitis and those from mixed hospital and antenatal patients could be accounted for by differences in handling and storage of the specimens, since positive sera proved stable despite repeated freezing and thawing. No common aetiological or other factors have been found among the acute pancreatitis patients showing this antibody 
pattern; nor is any explanation apparent for the small number of positive findings among the controls. It may be that several different antigens give rise to similar patterns within the pancreas. The subsequent fate of patients with positive antibody tests may prove of interest. The possibility exists that the antibodies described may delineate a sub-group of pancreatitis, bearing a particular long-term prognosis, and further clarification may emerge when other causes of acute pancreatitis, eg, viruses of different types, have been more thoroughly investigated.

We are deeply indebted to Professor Deborah Doniach of the Middlesex Hospital, and Professors L. Brent and P. Mollison and Dr V. S. Sljivic of St Mary's Hospital, W2 for helpful discussions; to Mr A. Bain and Mr G. Swana for technical advice and assistance; to Miss Jenny Smith and Mrs Marion Newlands for providing tissue and serum samples; to $\mathrm{Mr}$ A. Beasley for helpful technical assistance; to Mr J. L. Stephen and Mr M. E. Snell for making pancreatic tissue available; and to those physicians and surgeons at St Mary's Hospital W2 and W9, The Middlesex, Central Middlesex, and West Middlesex Hospitals who have allowed us to study their patients.

\section{References}

Banwo, O., Versey, J., and Hobbs, J. R. (1974). New oncofetal antigen for human pancreas. Lancet, 1, 643-645.

Bottazzo, G. F., Florin-Christensen, A., and Doniach, D. (1974). Islet-cell antibodies in diabetes mellitus with autoimmune polyendocrine deficiencies. Lancet, 2, 1279-1282.

Fonkalsrud, E. W., and Longmire, W. P., Jr. (1961). The occurrence of pancreatic antibodies and the experimental production of pancreatitis with pancreatic antiserum. Surgery, 50, 134-142.

Glynn, L. E., and Holborow, E. J. (1959). Distribution of bloodgroup substances in human tissues. Brit. med. Bull., 15, 150-153.

Greene, L. J., Hirs, C. H. W., and Palade, G. E. (1963). On the protein composition of bovine pancreatic zymogen granules. J. biol. Chem., 238, 2054-2070.

Herskovic, T., Alarçón-Segovia, D., Bartholomew, L. G., Cain, J. C., and Wakim, K. G. (1966). Immune mechanisms in chronic pancreatic disease. II. Serum precipitins to pancreatic homogenates in patients with pancreatic disease: Preliminary clinical observations. Amer. J. dig. Dis., 11, 40-44.

Hokin, L. E. (1955). Isolation of the zymogen granules of dog pan- creas and a study of their properties. Biochim. biophys. Acta. (Amst.), 18, 379-388.

Johnson, G. D., and Holborow, E. J. (1973). Immunofluorescence. In Handbook of Experimental Immunology, 2nd ed, vol. 1, edited by D. M. Weir, ch. 18, p. 15. Blackwell, Oxford.

Laird, A. K., and Barton, A. D. (1957). Protein synthesis in rat pancreas. I. Intracellular distribution of amylase. Biochim. biophys. Acta. (Amst.), 25, 56-62.

MacCuish, A. C., Barnes, E. W., Irvine, W. J., and Duncan, L. J. P. (1974). Antibodies to pancreatic islet cells in insulin-dependent diabetics with coexistent autoimmune disease. Lancet, 2, 1529-1531.

Marshall, J. M., Jr. (1954). Distributions of chymotrypsinogen, procarboxypeptidase, desoxyribonuclease and ribonuclease in bovine pancreas. Exp. Cell Res., 6, 240-242.

Metzgar, R. S. (1964a). Human pancreas-specific isoantigens. Nature (Lond.), 203, 660-661.

Metzgar, R. S. (1964b). Immunologic studies of pancreas-specific isoantigens. J. Immunol., 93, 176-182.

Mollison, P. L. (1972a). Blood Transfusion in Clinical Medicine, 5th ed, p. 452. Blackwell, Oxford.

Mollison, P. L. (1972b). Blood Transfusion in Clinical Medicine, 5th ed, p. 396. Blackwell, Oxford.

Moon, H. D., and McIvor, B. C. (1960). Elastase in the exocrine pancreas: localization with fluorescent antibody. J. Immunol., $85,78-80$.

Murray, M. J., and Thal, A. P. (1960). The clinical significance of circulating pancreatic antibodies. Ann. intern. Med., 53, 548-555.

Roitt, I. M., and Doniach, D. (1969). Immunofluorescent tests for the detection of autoantibodies. In WHO Manual of Autoimmune Serology, World Health Organization, Geneva.

Rose, N. R. (1965). Immunological specificity of the pancreas. In Immunopathology: Proceedings of the IVth International Symposium, edited by $P$. Grabar and $P$. A. Miescher, pp. 325-348. Schwabe, Basle.

Rothman, S. S. (1971). The behaviour of isolated zymogen granules: pH-dependent release and reassociation of protein. Biochim. biophys. Acta. (Amst.), 241, 567-577.

Stein, A. A., Manlapas, F. C., Soike, K. F., and Patterson, P. R. (1964). Specific isoantibodies in cystic fibrosis. J. Pediat., 65, 495-500.

Szulman, A. E. (1960). The histological distribution of blood group substances A and B in man. J.exp. Med., 111, 785-799.

Szulman, A. E. (1962). The histological distribution of the blood group substances in man as disclosed by immunofluorescence. II. The $\mathrm{H}$ antigen and its relation to $\mathrm{A}$ and $\mathrm{B}$ antigens. J. exp. Med., 115, 977-995.

Thal, A. P., Murray, M. J., and Egner, W. (1959). Isoantibody formation in chronic pancreatic disease. Lancet, 1, 1128-1129.

Van Lancker, J. L., and Holtzer, R. L. (1959). Tissue fractionation studies of mouse pancreas. J. biol. Chem., 234, 2359-2363.

Villavicencio, E., Thurnau, G., and Goetz, F. C. (1965). Isoantibodies to human pancreas. Diabetes, 14, 226-228.

Witebsky, E., Rose, N. R., and Nadel, H. (1960). Studies on organ specificity. X. The serologic specificity of pancreas extracts. $J$. Immunol., 85, 568-574.

Yasuda, K., and Coons, A. H. (1966). Localization by immunofluorescence of amylase, trypsinogen and chymotrypsinogen in the acinar cells of the pig pancreas.J. Histochem. Cytochem., 14, 303-313. 